Review Article

\title{
Adipose Stem Cell-Based Clinical Strategy for Neural Regeneration: A Review of Current Opinion
}

\author{
Yu-hao Wang $\mathbb{D}^{1,2,3}$ Yu-chen Guo $\mathbb{D}^{1,2}$ Dian-ri Wang $\mathbb{D}^{1,2,3}$ Ji-yuan Liu $\mathbb{D}^{1,2}$ \\ and Jian Pan iD $1,2,3$ \\ ${ }^{1}$ State Key Laboratory of Oral Disease, West China Hospital of Stomatology, Sichuan University, Chengdu 610041, China \\ ${ }^{2}$ National Clinical Research Center for Oral Diseases \& Department of Oral and Maxillofacial Surgery, West China Hospital \\ of Stomatology, Sichuan University, Chengdu 610041, China \\ ${ }^{3}$ National Engineering Laboratory for Oral Regenerative Medicine, West China Hospital of Stomatology, Sichuan University, \\ Chengdu, Sichuan Province 610041, China
}

Correspondence should be addressed to Jian Pan; jianpancn@scu.edu.cn

Received 5 September 2019; Revised 2 November 2019; Accepted 11 November 2019; Published 19 November 2019

Guest Editor: Roberto Narcisi

Copyright (c) 2019 Yu-hao Wang et al. This is an open access article distributed under the Creative Commons Attribution License, which permits unrestricted use, distribution, and reproduction in any medium, provided the original work is properly cited.

\begin{abstract}
Nerve injury is a critical problem in the clinic. Nerve injury causes serious clinic issues including pain and dysfunctions for patients. The disconnection between damaged neural fibers and muscles will result in muscle atrophy in a few weeks if no treatment is applied. Moreover, scientists have discovered that nerve injury can affect the osteogenic differentiation of skeletal stem cells (SSCs) and the fracture repairing. In plastic surgery, muscle atrophy and bone fracture after nerve injury have plagued clinicians for many years. How to promote neural regeneration is the core issue of research in the recent years. Without obvious effects of traditional neurosurgical treatments, research on stem cells in the past 10 years has provided a new therapeutic strategy for us to address this problem. Adipose stem cells (ASCs) are a kind of mesenchymal stem cells that have differentiation potential in adipose tissue. In the recent years, ASCs have become the focus of regenerative medicine. They play a pivotal role in tissue regeneration engineering. As a type of stem cell, ASCs are becoming popular for neuroregenerative medicine due to their advantages and characteristics. In the various diseases of the nervous system, ASCs are gradually applied to treat the related diseases. This review article focuses on the mechanism and clinical application of ASCs in nerve regeneration as well as the related research on ASCs over the past decades.
\end{abstract}

\section{Introduction}

Nerve injury is common in the clinic and leads to many other complications, such as muscle atrophy and abnormal bone reconstruction. The treatments of nerve injury cost USA medical insurance $\$ 150$ billion every year, and these diseases affect 20 million Americans' lives [1]. Nerve injury occurs in $2 \%$ to $3 \%$ of citizens, and more than 50,000 peripheral nerve injury repair operations are performed per year in the United States [2]. Therefore, nerve injury and its complications cause huge financial burdens for social development and affect patients' life quality. Thus, it is critical for clinicians to solve these urgent problems.

Nerve injury results in muscle atrophy and abnormal bone reconstruction which leads motor dysfunction. In gen- eral, satellite cells, as stem cells in skeletal muscle tissue, can repair atrophied and damaged skeletal muscles [3-7]. However, the recovery of damaged musculoskeletal tissue requires the involvement of nerve endings. It will form scar tissues without the involvement of nerve endings [8]. The loss of axonal continuity, nerve demyelination, and neuron cell death after nerve injury can lead to the denervation of skeletal muscle [2]. Some studies have demonstrated that muscle atrophy will happen after denervation within 2 weeks [9]. Furthermore, the accumulation ability of skeletal stem cells (SSCs) will decrease in the mandible with inferior alveolar nerve injury according to the Annual Clinical Congress of the American College of Surgeons in Boston, May 2018 [10]. Scientists attending the meeting have proved that nerve injury can affect the osteogenic differentiation of SSCs and 
delay the procedure of bone fracture repair [10]. The mandible is the core component of the masticatory system, and any damage to the mandible can cause masticatory muscle disorder. The recovery of damaged nerve may have a positive impact on the bone fracture repair, and briefly, it may provide a new strategy for skeletal muscle dysfunction and bone diseases.

The orthodox treatment for nerve injury can be divided into two major categories: surgical methods and nonsurgical methods. However, both surgical and nonsurgical methods have their own limitations. For example, Robinson et al. found that only 4 of 53 patients who underwent neurological direct suture had some degree of recovery [11]. The possible reason is that the length of nerve defect is so long that the sutured nerve has a large tension between the sutural endings. The majority of clinicians reject to use medication alone for treatment due to the long periodicity of drug therapy. At present, there are no effective methods to treat nerve injury in the clinic. Fortunately, the research on stem cells and tissue engineering in the past decades may make it possible.

\section{Stem Cells}

Stem cells can self-renew and differentiate into multiple lineages. Currently, scientists have isolated several kinds of adult stem cells, such as bone marrow mesenchymal stem cells (BM-MSCs), skeletal stem cells (SSCs), dental pulp stem cells (DPSCs), adipose stem cells (ASCs), neural stem cells (NSCs), fetal-derived stem cells (FDSCs), human periapical cyst-mesenchymal stem cells (hPCy-MSCs), induced pluripotent stem cells (iPSCs), skin epidermal stem cells (SESCs), human amniotic-mesenchymal stem cells (hAMSCs), and hair follicle stem cells (HFSCs) [12-14].

Stem cells in different tissues can expand their quantities by symmetrical division during the growth and development of the human body. Meanwhile, stem cells can self-renew and have great ability of multidirectional differentiation to replace damaged cells by asymmetric division when some injuries occur in different tissues. It has been reported that intravenous injection of MSCs can treat acute lung and kidney injuries in preclinical trials with mouse disease models $[15,16]$. ASCs derive from adipose tissues with some shared characteristics of all stem cells. More importantly, it is potential for ASCs to repair damaged tissues including nervous tissues.

\section{The Fate and Biological Characteristics of ASCs}

Easy obtainable methods with little damage for stem cell harvesting are the main ambition. The quantity of ASCs in adipose tissues is 100 - to 500 -fold compared with that of MSCs in bone marrow tissues. There are two types of human adipose tissue: white adipose tissue and brown adipose tissue. Subcutaneous adipose tissue in white adipose tissue is the main source of ASCs, and this kind of ASCs has a stronger antiapoptotic ability than ASCs located in brown adipose tissue [17]. However, ASCs from brown adipose tissue more easily undergo skeletal myogenic differentiation in the spe- cific microenvironment $[18,19]$. The characteristics of ASCs make them popular in the field of regeneration.

3.1. The Obtainable Method and Multipotential Differentiation of ASCs. It is widely accepted that ASCs can be harvested from adipose tissues and have great ability of multidirectional differentiation. With $0.075 \%$ collagenase type II digestion, ASCs can be harvested from the stromal vascular fraction (SVF) of adipose tissues. The ingredients of SVF include ASCs (15 30\%), endothelial cells (10-20\%), pericytes (3 5\%), and immune cells $(25 \sim 45 \%)$ [20, 21]. Due to the mesodermal origin of ASCs, they can differentiate into adipogenic, osteogenic, and chondrogenic lineages induced by selective medium in vitro $[22,23]$. Among them, the neural differentiation of ASCs has attracted scientists' attention and created a new cell-based clinical strategy for neurodegenerative diseases.

3.2. Neural Differentiation. Safford et al. firstly induced ASCs to differentiate into neuronal phenotype cells which express nestin and neuronal nuclei protein (NeuN) in 2002 [24]. The inducing and differentiation medium they used for neural differentiation of ASCs contained valproic acid, butyl hydroxyanisole, insulin, and hydrocortisone. However, this chemical method is not suitable to induce differentiation in vivo due to its disability to construct the corresponding microenvironment in the body for neural regeneration [25]. Moreover, chemical reagents in the medium can cause some extra damage to tissues, which brings pain to patients.

Biological induction methods are more suitable for repairing damaged tissues in vivo. ASCs can be induced to differentiate into neural cells if the medium contains some soluble factors secreted from nerve tissues which include cerebellum, hippocampus, and cerebral cortex [26]. ASCs can also secrete some neurotrophic factors in the process of neural differentiation, such as nerve growth factor (NGF), brainderived neurotrophic factor (BDNF), glial-derived neurotrophic factor (GDNF), ciliary neurotrophic factor (CNTF), and fibroblast growth factor (FGF) [27]. The current problem lies in how to control the direction of neural differentiation. Both neurons and glial cells can promote the remyelination of nerve which is of great importance for neural regeneration and express the similar markers [28-30]. However, some differences can be pointed out. A higher tendency of neuronal phenotype can be recognized when ASCs are induced by olfactory ensheathing cell conditioned medium (OEC-CM) $[31,32]$. Instead, ASCs are more likely to differentiate into glial cells in Schwann cell conditioned medium (SC-CM) with high concentration of GFAP [31,32].

ASCs can promote axonal regeneration, myelination, and functional recovery [33]. ASCs upregulate the expression of myelin protein zero, peripheral myelin protein-22, and myelin basic protein, which promotes self-regulation of ASC differentiation and reestablishes the connection between damaged nerve and target organs [34]. Some animal models have proved that ASCs have neuroprotection abilities and provide trophic supports for axon regeneration in optic nerve transection, glaucoma, and retinitis pigmentosa [35-37]. 
Furthermore, ASCs were applied to the preclinical trials for the CNS diseases, such as Alzheimer's disease (AD) and Parkinson's disease (PD) [38].

\section{The Regulation and Mechanism in the Neural Differentiation of ASCs}

There is a complex regulatory network in the neural differentiation of ASCs. In addition to neurotrophic factors secreted by ASCs, parts of signaling pathways are also involved in the differentiation courses. Most importantly, ASCs can promote their own neural differentiation by regulating the microenvironment. It is widely accepted that the microenvironment regulation interacts with the neural differentiation of ASCs [39]. The neural differentiation of ASCs takes place under complex regulatory mechanisms and promotes neural regeneration in order to repair damaged nervous tissues.

4.1. The Neurotrophic Effect. The paracrine function of stem cells is a kind of mechanism that accelerates the process of neural differentiation. Undifferentiated ASCs can secrete neuroprotective factors to enhance neural regeneration and reduce muscle atrophy $[40,41]$. These neuroprotective factors include BDNF, GDNF, CNTF, and neurotrophin-4 [41]. Furthermore, some angiogenesis and antiapoptotic factors are also secreted by ASCs, including hepatocyte growth factor (HGF), transforming growth factor- $\beta$ (TGF- $\beta$ ), and vascular endothelial growth factor (VEGF) [42-46]. Some scientists believe that the inhibition of apoptosis is a crucial step in tissue regeneration, which is decided by the concentration of antiapoptotic factors in the microenvironment [47]. Antiapoptotic factors and neurotrophic factors can promote neuron proliferation and survival $[48,49]$. Another important point is that the activation and proliferation of microglia accelerate the process of some neurodegenerative diseases, for example, traumatic brain injury (TBI) [50-54]. Jha et al. have proved that trophic factors secreted by ASCs can normalize microglia and slow down the development of neurodegenerative diseases [55].

Neurotrophic factor is a sort of protein molecule necessary for the growth and survival of neurons [56]. Among the known neurotrophic factors, BDNF is one of the most important factors in the development of the nervous system [41]. BDNF is a neural-related protein encoded early during the embryonic period and its genome is made of eight promoters, each of which binds to a common BDNF fulllength protein-encoding exon [57]. Transcription of BDNF is regulated by several mechanisms [58-60]. For example, the cAMP response element-binding protein (CREB) controls the transcription of exon IV and it is a key factor for the synaptic plasticity of neurons and cognition [61-64]. Furthermore, forskolin is a cAMP-elevating agent that can upregulate the expression of BDNF [65]. Recent studies have shown that the use of BDNF has a positive impact on synaptic plasticity, neuron-glia communication, and regulation of neurite outgrowth $[66,67]$. The neuron-glia communication is the foundation of neural maintenance. Glial cells can upregulate the expression of BDNF by receiving the signals from neurons [67-69].
4.2. The Microenvironment Regulation of ASCs. ASCs can improve the microenvironment for neural regeneration by inhibiting inflammatory responses [70]. Inflammation is induced by proinflammatory immune cells and cytokines and ASCs can secrete angiogenic factors to inhibit that process [71-74]. The newborn blood vessels ameliorate the microenvironment for tissue recovery while the inhibition of angiogenesis aggravates the progression and pathology of inflammation [75]. Black et al. found that ASCs reduced inflammatory response and demonstrated positive therapeutic effects on chronic inflammatory bowel disease in dogs [76]. ASCs can inhibit neural cell apoptosis by releasing anti-inflammatory factors and cytokines, which provide a stable microenvironment for the neural differentiation of ASCs [77].

The main anti-inflammatory factors secreted by ASCs include tumour necrosis factor-inducible gene 6 protein (TSG-6) and STC-1 [78-81]. TSG-6 is a component of the negative feedback mechanism and it can downregulate the inflammatory response [82]. Increasing evidences indicate that some paracrine factors secreted by ASCs are enough to alleviate inflammatory diseases in animal neural disease models $[78,80,83,84]$. The anti-inflammatory and immunomodulatory effects of these cytokines and chemokines are not only affected by the status of ASCs but are also affected by the concentration of TGF- $\beta 1$, tumour necrosis factor- $\alpha$ (TNF- $\alpha$ ), lipopolysaccharide (LPS), and hypoxia in microenvironments [85-88]. Taken together, the interaction between the neural differentiation of ASCs and the regulation of the microenvironment has a positive influence on inflammatory inhibition.

4.3. The Regulation of Signaling Pathways. Since the discovery of the signaling pathways was introduced, scientists have discovered that most of cell physiology can be explained by the regulation of signaling pathways. The neural differentiation of ASCs is also regulated by multiple signaling pathways. Here, we reviewed several known signaling pathways involved in the neural differentiation process.

Researchers have discovered that the Wnt signaling pathway is involved in the formation of the brain. The Wnt/LEF/TCF genes work synergistically to participate in the development of the hippocampal gyrus, and Wnt3a knockout can stop the development of hippocampus in mouse embryos [89-91]. In addition, the Wnt signaling pathway is also involved in the initiation of axon formation. Wnt7a can induce the reconstitution of axons and growth cones in mossy nerve fibers, as well as the collection of receptors I [91]. In contrast, Jang et al. have demonstrated that the classical Wnt signaling pathway does not regulate the neural differentiation of ASCs. Instead, they have proved that the noncanonical Wnt signaling pathway activates the neural differentiation of ASCs by regulating the activation/phosphorylation of Wnt5a/JNK signaling pathway [92].

Some other signaling pathways have been found to participate in the neural differentiation process, such as ROCK and $\mathrm{BDNF} / \mathrm{TrkB}$ signaling pathway. Ren et al. have proved that the ROCK pathway inhibitor, namely, Y-27632, could accelerate the neural differentiation of ASCs in their 
experiment. After adding Y-27632 into the culture medium, the shape of mouse ASCs switched to neuronal-like cells. Furthermore, the cells lost their neuron-like morphology once Y-27632 was removed from the medium [93]. It indicates that the ROCK signaling pathway inhibits the neural differentiation of ASCs. Some scholars have pointed out that ASCs may be also regulated by the BDNF/TrkB signaling pathway during the neural differentiation [84]. The BDNF/TrkB signaling pathway induces the secretion of BDNF which is a neurotrophic factor which can promote the neural differentiation of ASCs as previously mentioned [85]. However, scientists are not sure how these multiple signaling pathways interplay in the neural differentiation of ASCs. More research is needed in this field.

\section{The Prospects for Clinical Application of ASCs in Neural Disease}

Due to the limited therapeutic effect of clinical methods, treatment for nerve injury cannot keep pace with the life quality of people. Many elderly people suffer from nervous system diseases around the world. For example, the organic chemical pollution in water always causes serious nervous system diseases in developing countries and backward regions. Nerve injury not only leads to neurological disorders but also musculoskeletal system damage. Taking into account the limitations of current therapeutic methods, the application of stem cell-based therapy is extremely urgent.

The occurrence of neurodegenerative diseases involves a variety of pathophysiological mechanisms that determine the progress and severity of the diseases including neuroinflammation, mitochondrial dysfunction, and protein aggregation [94]. There are several common neurodegenerative diseases in the clinic, such as $\mathrm{AD}, \mathrm{PD}, \mathrm{TBI}$, and spinal cord injury (SCI). In addition to their own ability to differentiate into nerve cells, ASCs can also secrete various neurotrophic factors and immune regulatory mediators. In the recent years, clinical application of ASCs has attracted much attention in the field of regenerative medicine.

5.1. $A D . \mathrm{AD}$ is a neurological degenerative disease with family heritability [95]. It is characterized by generalized dementia, such as memory impairment, loss of recognition, abnormal motion, and personality and behavioural change. $\mathrm{AD}$ may be a heterogeneous group of diseases, which is regulated by a variety of factors, including biological and psychosocial factors. Entanglement of amyloid- $\beta$ plaques and neuronal fibers, neurodegeneration of the limbic system, and neural progressive decline are the main pathological features of $\mathrm{AD}$ [96].

Kim et al. have proved that the application of ASCs in the $\mathrm{AD}$ mouse experimental models was feasible [97]. In their study, the Morris water maze test (MWM) of mice was significantly improved. They found that $\mathrm{A} \beta$ plaque formations were reduced in the cerebral cortex. Amyloid precursor protein (APP) levels were reduced and $A \beta$-degrading enzyme levels were also upregulated. These phenomena clearly showed that the symptom of $\mathrm{AD}$ has been ameliorated. In another experiment, ASCs increased the secretion of anti- inflammatory factors, enhancing the expression of $\mathrm{A} \beta$ degrading enzymes and raising the response levels in cognitive and memory tests [38]. Furthermore, ASCs increased the secretion of interleukin-10 and induced microglia to polarize the activation phenotype as well as express several vascular and neurotrophic factors $[38,97,98]$. In the recent years, Pérez-González et al. found that ASCs could secrete leptin during neural differentiation. Leptin is a kind of protein hormone which promotes the neural regeneration of stem cells in vitro and slows down the process of neurodegenerative diseases in vivo [99].

5.2. $P D$. PD is a common degenerative disease of the nervous system in the elderly. The main pathological features of PD are progressive dopaminergic neuron loss in the substantia nigra pars compacta. Tremor, muscle rigidity, and decreased motion are the main clinical features of PD. Zhang et al. have found that PD patients always had chest muscle tissue tension which lead to breath function disorder [100]. It shows that the nervous system damage of PD is not the most fatal factor for patients. Dyspnea and its complications caused by $\mathrm{PD}$ are the greatest harm to the human body.

In animal experimental models of $\mathrm{PD}$, ASCs upregulated the secretion of soluble growth factors including antiinflammatory factors and BDNF [101]. BDNF is an important neurotropic factor which can promote differentiation of stem cells and anti-inflammatory can improve the microenvironment as described earlier. The ASC-based regenerative therapy has a huge potential to treat $\mathrm{PD}$ and provides us a new strategy to improve neural and musculoskeletal tissue function for PD patients. However, Schwerk et al. found that the function of regenerative dopaminergic neurons induced by ASCs cannot completely replace that of lost dopaminergic neurons [102]. Furthermore, some scientists demonstrated that ASCs cannot improve the survival rate of $\mathrm{PD}$ patients after clinical treatment [103]. More research is required to clarify whether ASCs are useful in the treatment of PD.

5.3. SCI. SCI is one of the common symptoms in serious traumas caused by car accidents or falls. Serious injury to the limbs and muscle atrophy due to disconnection between muscles and damaged nerves disturb the ordinary life of patients. Thousands of SCI patients impose a huge burden on the development of social economy, and it costs billions of dollars every year [1]. The prevention, treatment, and rehabilitation of SCI have become a major issue in the medical field due to its urgency for patients and society.

Some studies have shown that ASCs can survive and migrate to damaged nerve tissue in animal experimental models [104]. Meanwhile, transplanted ASCs express GFAP and neuronal nuclear antigens in ischaemic encephalopathy [105]. In a previous study, the expression of GFAP, NF160, and Tuj-1 of ASCs was positive after transplanted ASCs were inserted into lentiviral vectors that were GFP-tagged in SCI models [8]. It is suggested that the implantation of ASCs can differentiate into astrocytes and oligodendrocytes as well as neurons. Neurons deriving from differentiation can 
convey regenerative information from proximal-disruptingending neural fibers to the distal side [106].

The neural regeneration in SCI has a positive effect on innervation to muscle after peripheral nerve injury. When the peripheral nerve breaks down, the skeletal muscle which is innervated by the damaged nerve degenerates and muscle atrophy occurs. The neural transdifferentiation process may be the consequence of cytokine secretion, the interactions of ASCs and intercellular signaling pathways of ASCs [107]. Also, ASCs have been shown to secrete a variety of angiogenic and antiapoptotic cytokines, which support tissue regeneration and minimize tissue damage [108].

5.4. TBI. TBI is a type of disruption or alteration of brain function caused by external forces. Skull fracture and intracranial hypertension caused by TBI can lead to conscious disturbance, headache, and vomiting which are transient or long-lasting clinical symptoms of patients. External forces that cause TBI include acceleration or deceleration, direct compression, penetration of objects, and explosion damage. In the United States, the top three causes of TBI are fall (28\%), motor vehicle accidents (20\%), and pedestrian impact (19\%) [109]. Masel and Dewitt thought that TBI is a cascade process involving primary and secondary brain injury instead of a simple external force injury process [110]. Primary damage refers to mechanical damage to the brain tissue caused by external forces. Secondary damage is a cellular metabolic event that occurs after an external force injury [111]. Within 24 hours after the brain tissue injury, the blood-brain barrier has been damaged and inflammatory cells enter the brain tissue leading to the occurrence of inflammation.

Tajiri et al. have proved that ASCs and ASC-associated secreted proteins can reduce cortical damage in mouse TBI models [112]. But the experimental mice were killed at an early stage, and the relevant mechanisms have not been proved. However, a possible mechanism is increasingly supported in scholars: inflammatory suppression theory [113]. Regarding these patients suffering TBI, inflammatory cells release kinds of immune-mediated factors. It is often considered as a secondary brain injury $[114,115]$. TNF- $\alpha$, as a kind of inflammatory factor, mainly predominates the inflammatory response [116, 117]. Controlling the inflammatory response after injury can be thought as a target for the TBI treatment. Kappy et al. have demonstrated that ASCs and its own secreting proteins downregulate the secretion of inflammatory factors and inhibit the inflammation in TBI [118-120].

Furthermore, $\beta$-APP is thought to be an important marker of nerve damage [121]. $\beta$-APP is a complete membrane protein with a high concentration in neuronal synapses. The role of $\beta$-APP in the brain has not been clarified, but the concentration of $\beta$-APP has been found increasing in the mouse TBI model [121]. $\beta$-APP can be used as a marker for diagnosing nerve damage and assessing the severity of TBI [122]. In Kappy's experiment, inserting ASCs into TBI mouse maintains the $\beta$-APP concentration instead of making the concentration of $\beta$-APP continuously increasing
[118]. It suggests that ASCs play a neuroprotective role in the TBI model.

\section{Conclusion}

Stem cells have great abilities of multidirectional differentiation and are widely found in nearly all organs and tissues except the heart. When human tissues or organs are damaged or diseased, stem cells can differentiate into corresponding progenitor cells and replenish the cell pools to recover normal function of organs. However, due to the particularity of the nervous system, nerves are less able to self-regenerate. The nerve injury is not only limited to the nerve tissues but also often affects the musculoskeletal tissues. Muscle atrophy and scar formation can be effectively prevented by neural regeneration. At present, the clinical therapy for neurodegenerative diseases mainly includes surgical and nonsurgical means, such as neurolysis, direct nerve suture, and drug treatment. Although these methods have been proved to have a degree of curative effect, it has not lived up to expectations. In recent years, stem cell-based therapies are expected to replace orthodox treatment.

ASCs that are isolated from adipose tissue can differentiate into other kinds of cells with a low mortality rate in vivo and in vitro. ASCs have advantages of easy material extraction, which means that they could be extracted from many types of tissues with slight damage to the body. Most importantly, ASCs are characterized by low immunogenicity and are not susceptible to immune rejection. Considering the advantages above, we are looking forward to a fact that ASCs will play a crucial role in the treatment of various tissue and organ diseases. In particular, in the nervous system, ASCs are important for promoting neural regeneration. The neurogenic and osteogenic differentiation of ASCs accelerates the recovery of damaged tissues. It will provide a new method for orthodox treatments. However, there are still many issues in the field of neural regeneration with ASCs. For example, the neural differentiation ability of ASCs extracted from different tissues should be clarified in order to identify the most efficacious ASC source for neural regeneration. More research is needed in the field for clinical application. We truly believe that ASCs would play a signature role for neural regeneration in the future.

\section{Abbreviations}

$\begin{array}{ll}\text { AD: } & \text { Alzheimer's disease } \\ \text { APP: } & \text { Amyloid precursor protein } \\ \text { ASCs: } & \text { Adipose stem cells } \\ \text { BDNF: } & \text { Brain-derived neurotrophic factor } \\ \text { BM-MSCs: } & \text { Bone marrow mesenchymal stem cells } \\ \text { CNS: } & \text { Central nervous system } \\ \text { CNTF: } & \text { Ciliary neurotrophic factor } \\ \text { CREB: } & \text { cAMP response element-binding protein } \\ \text { DPSCs: } & \text { Dental pulp stem cells } \\ \text { FDSCs: } & \text { Fetal-derived stem cells } \\ \text { FGF: } & \text { Fibroblast growth factor } \\ \text { GDNF: } & \text { Glial-derived neurotrophic factor } \\ \text { GFAP: } & \text { Glial fibrillary acidic protein }\end{array}$




$\begin{array}{ll}\text { HGF: } & \text { Hepatocyte growth factor } \\ \text { HFSCs: } & \text { Hair follicle stem cells } \\ \text { hPCy-MSCs: } & \text { Human apical cyst-mesenchymal stem cells } \\ \text { iPSCs: } & \text { Induced pluripotent stem cells } \\ \text { LPS: } & \text { Lipopolysaccharide } \\ \text { MSCs: } & \text { Mesenchymal stem cells } \\ \text { MWM: } & \text { Morris water maze test } \\ \text { NeuN: } & \text { Neuronal nuclei protein } \\ \text { NGF: } & \text { Nerve growth factor } \\ \text { NSCs: } & \text { Neural stem cells } \\ \text { OEC-CM: } & \text { Olfactory ensheathing cell conditioned medium } \\ \text { PD: } & \text { Parkinson's disease } \\ \text { PNS: } & \text { Peripheral nervous system } \\ \text { SC-CM: } & \text { Schwann cell conditioned medium } \\ \text { SCI: } & \text { Spinal cord injury } \\ \text { SESCs: } & \text { Skin epidermal stem cells } \\ \text { SSCs: } & \text { Skeletal stem cells } \\ \text { SVF: } & \text { Stromal vascular fraction } \\ \text { TBI: } & \text { Traumatic brain injury } \\ \text { TGF- } \beta: & \text { Transforming growth factor- } \beta \\ \text { TNF- } \alpha: & \text { Tumour necrosis factor- } \alpha \\ \text { TSG-6: } & \text { Tumour necrosis factor-inducible gene } 6 \\ & \text { protein } \\ \text { VEGF: } & \text { Vascular endothelial growth factor. } \\ & \end{array}$

\section{Conflicts of Interest}

The authors declare no conflict of interests.

\section{Acknowledgments}

This work was supported by grants from the project of Science \& Technology Department of Sichuan Province (2017SZ0094) and the project of Science \& Technology Bureau of Chengdu (2016-HM01-00071-SF).

\section{References}

[1] D. Grinsell and C. P. Keating, "Peripheral nerve reconstruction after injury: a review of clinical and experimental therapies," Biomed Research International, vol. 2014, Article ID 698256, 13 pages, 2014

[2] L. Yue, M. A. Talukder, A. Gurjar et al., "4-Aminopyridine attenuates muscle atrophy after sciatic nerve crush injury in mice," Muscle \& Nerve, vol. 60, no. 2, pp. 192-201, 2019.

[3] J. Gros, M. Manceau, V. Thomé, and C. Marcelle, "A common somitic origin for embryonic muscle progenitors and satellite cells," Nature, vol. 435, no. 7044, pp. 954-958, 2005.

[4] P. Seale, L. A. Sabourin, A. Girgis-Gabardo, A. Mansouri, P. Gruss, and M. A. Rudnicki, "Pax7 is required for the specification of myogenic satellite cells," Cell, vol. 102, no. 6, pp. 777-786, 2000.

[5] M. Cerletti, S. Jurga, C. A. Witczak et al., "Highly efficient, functional engraftment of skeletal muscle stem cells in dystrophic muscles," Cell, vol. 134, no. 1, pp. 37-47, 2008.

[6] S. Fukada, S. Higuchi, M. Segawa et al., "Purification and cellsurface marker characterization of quiescent satellite cells from murine skeletal muscle by a novel monoclonal antibody," Experimental Cell Research, vol. 296, no. 2, pp. 245$255,2004$.
[7] S. Kuang, K. Kuroda, F. le Grand, and M. A. Rudnicki, "Asymmetric self-renewal and commitment of satellite stem cells in muscle," Cell, vol. 129, no. 5, pp. 999-1010, 2007.

[8] H. H. Ryu, J. H. Lim, Y. E. Byeon et al., "Functional recovery and neural differentiation after transplantation of allogenic adipose-derived stem cells in a canine model of acute spinal cord injury," Journal of Veterinary Science, vol. 10, no. 4, pp. 273-284, 2009.

[9] V. Moresi, A. H. Williams, E. Meadows et al., "Myogenin and class II HDACs control neurogenic muscle atrophy by inducing E3 ubiquitin ligases," Cell, vol. 143, no. 1, pp. 35-45, 2010.

[10] R. E. Jones, R. C. Ransom, A. Salhotra, D. S. Foster, D. C. Wan, and M. T. Longaker, "Nerve-dependent mandibular regeneration by skeletal stem cells in fracture repair," Journal of the American College of Surgeons, vol. 227, no. 4, p. S197, 2018.

[11] P. P. Robinson, A. R. Loescher, and K. G. Smith, "A prospective, quantitative study on the clinical outcome of lingual nerve repair," British Journal of Oral \& Maxillofacial Surgery, vol. 38, no. 4, pp. 255-263, 2000.

[12] N. G. Fairbairn, A. M. Meppelink, J. Ng-Glazier, M. A. Randolph, and J. M. Winograd, "Augmenting peripheral nerve regeneration using stem cells: a review of current opinion," World Journal of Stem Cells, vol. 7, no. 1, pp. 11-26, 2015.

[13] Y. Guo, W. Wu, X. Ma, M. Shi, and X. Yang, "Comparative gene expression profiling reveals key pathways and genes different in skin epidermal stem cells and corneal epithelial cells," Genes \& Genomics, vol. 41, no. 6, pp. 679-688, 2019.

[14] H. C. Pan, D. Y. Yang, Y. T. Chiu et al., "Enhanced regeneration in injured sciatic nerve by human amniotic mesenchymal stem cell," Journal of Clinical Neuroscience, vol. 13, no. 5, pp. 570-575, 2006.

[15] A. Monsel, Y. G. Zhu, S. Gennai, Q. Hao, J. Liu, and J. W. Lee, "Cell-based therapy for acute organ injury: preclinical evidence and on-going clinical trials using mesenchymal stem cells," Anesthesiology, vol. 121, no. 5, pp. 1099-1121, 2014.

[16] S. Bruno and B. Bussolati, "Therapeutic effects of mesenchymal stem cells on renal ischemia-reperfusion injury: a matter of genetic transfer?," Stem Cell Research \& Therapy, vol. 4, no. 5, p. 55, 2013.

[17] J. W. Kuhbier, B. Weyand, C. Radtke, P. M. Vogt, C. Kasper, and K. Reimers, "Isolation, characterization, differentiation, and application of adipose-derived stem cells," in Bioreactor Systems for Tissue Engineering II, vol. 123, pp. 55-105, Springer, Berlin, Heidelberg, 2010.

[18] E. Raposio and N. Bertozzi, "Isolation of ready-to-use adipose-derived stem cell (ASC) pellet for clinical applications and a comparative overview of alternate methods for ASC isolation," Current Protocols in Stem Cell Biology, vol. 41, no. 1, pp. 1F.17.1-1F.17.12, 2017.

[19] E. Raposio and N. Bertozzi, "How to isolate a ready-to-use adipose-derived stem cells pellet for clinical application," European Review for Medical and Pharmacological Sciences, vol. 21, no. 18, pp. 4252-4260, 2017.

[20] O. DelaRosa, B. Sánchez-Correa, S. Morgado et al., "Human adipose-derived stem cells impair natural killer cell function and exhibit low susceptibility to natural killer-mediated lysis," Stem Cells and Development, vol. 21, no. 8, pp. 1333 1343, 2012. 
[21] J. M. Gimble, A. J. Katz, and B. A. Bunnell, "Adipose-derived stem cells for regenerative medicine," Circulation Research, vol. 100, no. 9, pp. 1249-1260, 2007.

[22] C. Radtke, B. Schmitz, M. Spies, J. D. Kocsis, and P. M. Vogt, "Peripheral glial cell differentiation from neurospheres derived from adipose mesenchymal stem cells," International Journal of Developmental Neuroscience, vol. 27, no. 8, pp. 817-823, 2009.

[23] S. G. Almalki and D. K. Agrawal, "Key transcription factors in the differentiation of mesenchymal stem cells," Differentiation, vol. 92, no. 1-2, pp. 41-51, 2016.

[24] K. M. Safford, K. C. Hicok, S. D. Safford et al., "Neurogenic differentiation of murine and human adipose-derived stromal cells," Biochemical and Biophysical Research Communications, vol. 294, no. 2, pp. 371-379, 2002.

[25] A.-M. Rodriguez, C. Elabd, E. Z. Amri, G. Ailhaud, and C. Dani, "The human adipose tissue is a source of multipotent stem cells," Biochimie, vol. 87, no. 1, pp. 125-128, 2005.

[26] C. Han, L. Song, Y. Liu, W. Zou, C. Jiang, and J. Liu, "Rat cortex and hippocampus-derived soluble factors for the induction of adipose-derived mesenchymal stem cells into neuron-like cells," Cell Biology International, vol. 38, no. 6, pp. 768-776, 2014.

[27] J. D. Kocsis, K. L. Lankford, M. Sasaki, and C. Radtke, "Unique in vivo properties of olfactory ensheathing cells that may contribute to neural repair and protection following spinal cord injury," Neuroscience Letters, vol. 456, no. 3, pp. 137142, 2009.

[28] M. Barton, J. John, M. Clarke, A. Wright, and J. Ekberg, "The glia response after peripheral nerve injury: a comparison between Schwann cells and olfactory ensheathing cells and their uses for neural regenerative therapies," International Journal of Molecular Sciences, vol. 18, no. 2, p. 287, 2017.

[29] M. Gu, Z. Gao, X. Li et al., "Conditioned medium of olfactory ensheathing cells promotes the functional recovery and axonal regeneration after contusive spinal cord injury," Brain Research, vol. 1654, no. Part A, pp. 43-54, 2017.

[30] R. Pellitteri, M. Spatuzza, S. Stanzani, and D. Zaccheo, "Biomarkers expression in rat olfactory ensheathing cells," Frontiers in Bioscience, vol. S2, no. 1, pp. 289-298, 2010.

[31] D. Lo Furno, G. Mannino, R. Giuffrida et al., "Neural differentiation of human adipose-derived mesenchymal stem cells induced by glial cell conditioned media," Journal of Cellular Physiology, vol. 233, no. 10, pp. 7091-7100, 2018.

[32] D. Lo Furno, G. Mannino, R. Pellitteri et al., "Conditioned media from glial cells promote a neural-like connexin expression in human adipose-derived mesenchymal stem cells," Frontiers in Physiology, vol. 9, p. 1742, 2018.

[33] K. Tomita, T. Madura, C. Mantovani, and G. Terenghi, "Differentiated adipose-derived stem cells promote myelination and enhance functional recovery in a rat model of chronic denervation," Journal of Neuroscience Research, vol. 90, no. 7, pp. 1392-1402, 2012.

[34] C. Mantovani, D. Mahay, M. Kingham, G. Terenghi, S. G. Shawcross, and M. Wiberg, "Bone marrow- and adiposederived stem cells show expression of myelin mRNAs and proteins," Regenerative Medicine, vol. 5, no. 3, pp. 403-410, 2010.

[35] S. Sugitani, K. Tsuruma, Y. Ohno et al., "The potential neuroprotective effect of human adipose stem cells conditioned medium against light-induced retinal damage," Experimental Eye Research, vol. 116, pp. 254-264, 2013.

[36] B. Mead, L. J. Hill, R. J. Blanch et al., "Mesenchymal stromal cell-mediated neuroprotection and functional preservation of retinal ganglion cells in a rodent model of glaucoma," Cytotherapy, vol. 18, no. 4, pp. 487-496, 2016.

[37] T. V. Johnson, N. D. Bull, D. P. Hunt, N. Marina, S. I. Tomarev, and K. R. Martin, "Neuroprotective effects of intravitreal mesenchymal stem cell transplantation in experimental glaucoma," Investigative Ophthalmology \& Visual Science, vol. 51, no. 4, pp. 2051-2059, 2010.

[38] T. Ma, K. Gong, Q. Ao et al., "Intracerebral transplantation of adipose-derived mesenchymal stem cells alternatively activates microglia and ameliorates neuropathological deficits in Alzheimer's disease mice," Cell Transplantation, vol. 22, 1_suppl, pp. 113-126, 2013.

[39] A. C. E. Graziano, R. Avola, V. Perciavalle et al., "Physiologically based microenvironment for in vitro neural differentiation of adipose-derived stem cells," World Journal of Stem Cells, vol. 10, no. 3, pp. 23-33, 2018.

[40] L. Y. Santiago, J. Clavijo-Alvarez, C. Brayfield, J. P. Rubin, and K. G. Marra, "Delivery of adipose-derived precursor cells for peripheral nerve repair," Cell Transplantation, vol. 18, no. 2, pp. 145-158, 2009.

[41] X. Wei, L. Zhao, J. Zhong et al., "Adipose stromal cellssecreted neuroprotective media against neuronal apoptosis," Neuroscience Letters, vol. 462, no. 1, pp. 76-79, 2009.

[42] A. Miranville, C. Heeschen, C. Sengenès, C. A. Curat, R. Busse, and A. Bouloumié, "Improvement of postnatal neovascularization by human adipose tissue-derived stem cells," Circulation, vol. 110, no. 3, pp. 349-355, 2004.

[43] H. Nakagami, K. Maeda, R. Morishita et al., "Novel autologous cell therapy in ischemic limb disease through growth factor secretion by cultured adipose tissue-derived stromal cells," Arteriosclerosis, Thrombosis, and Vascular Biology, vol. 25, no. 12, pp. 2542-2547, 2005.

[44] V. Planat-Benard, J. S. Silvestre, B. Cousin et al., "Plasticity of human adipose lineage cells toward endothelial cells: physiological and therapeutic perspectives," Circulation, vol. 109, no. 5, pp. 656-663, 2004.

[45] J. Rehman, D. Traktuev, J. Li et al., "Secretion of angiogenic and antiapoptotic factors by human adipose stromal cells," Circulation, vol. 109, no. 10, pp. 1292-1298, 2004.

[46] S. Sadat, S. Gehmert, Y. H. Song et al., "The cardioprotective effect of mesenchymal stem cells is mediated by IGF-I and VEGF," Biochemical and Biophysical Research Communications, vol. 363, no. 3, pp. 674-679, 2007.

[47] O. Ekshyyan and T. Aw, "Apoptosis: a key in neurodegenerative disorders," Current Neurovascular Research, vol. 1, no. 4, pp. 355-371, 2004.

[48] A. Blesch, "Neurotrophic factors in neurodegeneration," Brain Pathology, vol. 16, no. 4, pp. 295-303, 2006.

[49] M. Dragunow, G. A. MacGibbon, P. Lawlor et al., "Apoptosis, neurotrophic factors and neurodegeneration," Reviews in the Neurosciences, vol. 8, no. 3-4, pp. 223-265, 1997.

[50] J. R. Perez-Polo, H. C. Rea, K. M. Johnson et al., "Inflammatory consequences in a rodent model of mild traumatic brain injury," Journal of Neurotrauma, vol. 30, no. 9, pp. 727-740, 2013.

[51] T. Cao, T. C. Thomas, J. M. Ziebell, J. R. Pauly, and J. Lifshitz, "Morphological and genetic activation of microglia after 
diffuse traumatic brain injury in the rat," Neuroscience, vol. 225, pp. 65-75, 2012.

[52] A. Kumar, D. M. Alvarez-Croda, B. A. Stoica, A. I. Faden, and D. J. Loane, "Microglial/macrophage polarization dynamics following traumatic brain injury," Journal of Neurotrauma, vol. 33, no. 19, pp. 1732-1750, 2016.

[53] M. Das, S. Mohapatra, and S. S. Mohapatra, "New perspectives on central and peripheral immune responses to acute traumatic brain injury," Journal of Neuroinflammation, vol. 9, no. 1, 2012.

[54] J. B. Redell and P. K. Dash, "Traumatic brain injury stimulates hippocampal catechol- $\mathrm{O}$-methyl transferase expression in microglia," Neuroscience Letters, vol. 413, no. 1, pp. 36-41, 2007.

[55] K. Jha, M. Pentecost, R. Lenin et al., "Concentrated conditioned media from adipose tissue derived mesenchymal stem cells mitigates visual deficits and retinal inflammation following mild traumatic brain injury," International Journal of Molecular Sciences, vol. 19, no. 7, p. 2016, 2018.

[56] A. I. Caplan and J. E. Dennis, "Mesenchymal stem cells as trophic mediators," Journal of Cellular Biochemistry, vol. 98, no. 5, pp. 1076-1084, 2006.

[57] T. Aid, A. Kazantseva, M. Piirsoo, K. Palm, and T. Timmusk, "Mouse and rat BDNF gene structure and expression revisited," Journal of Neuroscience Research, vol. 85, no. 3, pp. 525-535, 2007.

[58] A. E. West, E. C. Griffith, and M. E. Greenberg, "Regulation of transcription factors by neuronal activity," Nature Reviews Neuroscience, vol. 3, no. 12, pp. 921-931, 2002.

[59] A. E. West, W. G. Chen, M. B. Dalva et al., "Calcium regulation of neuronal gene expression," Proceedings of the National Academy of Sciences, vol. 98, no. 20, pp. 1102411031, 2001.

[60] P. L. Greer and M. E. Greenberg, "From synapse to nucleus: calcium-dependent gene transcription in the control of synapse development and function," Neuron, vol. 59, no. 6, pp. 846-860, 2008.

[61] X. Tao, S. Finkbeiner, D. B. Arnold, A. J. Shaywitz, and M. E. Greenberg, "Ca ${ }^{2+}$ Influx Regulates BDNF Transcription by a CREB Family Transcription Factor-Dependent Mechanism," Neuron, vol. 20, no. 4, pp. 709-726, 1998.

[62] P. B. Shieh, S. C. Hu, K. Bobb, T. Timmusk, and A. Ghosh, "Identification of a signaling pathway involved in calcium regulation of BDNF expression," Neuron, vol. 20, no. 4, pp. 727-740, 1998.

[63] Z. Zhou, E. J. Hong, S. Cohen et al., "Brain-Specific Phosphorylation of MeCP2 Regulates Activity-Dependent Bdnf Transcription, Dendritic Growth, and Spine Maturation," Neuron, vol. 52, no. 2, pp. 255-269, 2006.

[64] F. D. Lubin, T. L. Roth, and J. D. Sweatt, "Epigenetic regulation of bdnf gene transcription in the consolidation of fear memory," Journal of Neuroscience, vol. 28, no. 42, pp. 10576-10586, 2008.

[65] K. H. Tse, L. N. Novikov, M. Wiberg, and P. J. Kingham, "Intrinsic mechanisms underlying the neurotrophic activity of adipose derived stem cells," Experimental Cell Research, vol. 331, no. 1, pp. 142-151, 2015.

[66] R. D. Fields and G. Burnstock, "Purinergic signalling in neuron-glia interactions," Nature Reviews Neuroscience, vol. 7, no. 6, pp. 423-436, 2006.
[67] I. Takasaki, S. Takarada, S. Tatsumi et al., "Extracellular adenosine $5^{\prime}$-triphosphate elicits the expression of brainderived neurotrophic factor exon IV mRNA in rat astrocytes," Glia, vol. 56, no. 13, pp. 1369-1379, 2008.

[68] C. Verderio, F. Bianco, M. P. Blanchard et al., "Cross talk between vestibular neurons and Schwann cells mediates BDNF release and neuronal regeneration," Brain Cell Biology, vol. 35, no. 2-3, pp. 187-201, 2006.

[69] M. E. Gomez-Casati, J. C. Murtie, C. Rio, K. Stankovic, M. C. Liberman, and G. Corfas, "Nonneuronal cells regulate synapse formation in the vestibular sensory epithelium via erbBdependent BDNF expression," Proceedings of the National Academy of Sciences, vol. 107, no. 39, pp. 17005-17010, 2010.

[70] Z. Zhu, Z. Q. Yuan, C. Huang et al., "Pre-culture of adiposederived stem cells and heterologous acellular dermal matrix: paracrine functions promote post-implantation neovascularization and attenuate inflammatory response," Biomedical Materials, vol. 14, no. 3, 2019.

[71] M. Duijvestein, M. E. Wildenberg, M. M. Welling et al., "Pretreatment with interferon- $\gamma$ enhances the therapeutic activity of mesenchymal stromal cells in animal models of colitis," Stem Cells, vol. 29, no. 10, pp. 1549-1558, 2011.

[72] K. Nagaishi, Y. Arimura, and M. Fujimiya, "Stem cell therapy for inflammatory bowel disease," Journal of Gastroenterology, vol. 50, no. 3, pp. 280-286, 2015.

[73] C. Grégoire, C. Lechanteur, A. Briquet et al., "Review article: mesenchymal stromal cell therapy for inflammatory bowel diseases," Alimentary Pharmacology \& Therapeutics, vol. 45, no. 2, pp. 205-221, 2017.

[74] M. Dave, P. Jaiswal, and F. Cominelli, "Mesenchymal stem/stromal cell therapy for inflammatory bowel disease: an updated review with maintenance of remission," Current Opinion in Gastroenterology, vol. 33, no. 1, pp. 5968, 2017.

[75] J. H. Chidlow Jr., D. Shukla, M. B. Grisham, and C. G. Kevil, "Pathogenic angiogenesis in IBD and experimental colitis: new ideas and therapeutic avenues," American Journal of Physiology-Gastrointestinal and Liver Physiology, vol. 293, no. 1, pp. G5-G18, 2007.

[76] L. L. Black, J. Gaynor, D. Gahring et al., "Effect of adiposederived mesenchymal stem and regenerative cells on lameness in dogs with chronic osteoarthritis of the coxofemoral joints: a randomized, double-blinded, multicenter, controlled trial," Veterinary Therapeutics, vol. 8, no. 4, pp. 272-284, 2007.

[77] K. Marycz, I. Michalak, I. Kocherova, M. Maredziak, and C. Weiss, "The Cladophora glomerata enriched by biosorption process in $\mathrm{Cr}(\mathrm{III})$ improves viability, and reduces oxidative stress and apoptosis in equine metabolic syndrome derived adipose mesenchymal stromal stem cells (ASCs) and their extracellular vesicles (MV's)," Marine Drugs, vol. 15, no. 12, p. 385, 2017.

[78] H. Choi, R. H. Lee, N. Bazhanov, J. Y. Oh, and D. J. Prockop, "Anti-inflammatory protein TSG-6 secreted by activated MSCs attenuates zymosan-induced mouse peritonitis by decreasing TLR2/NF- $\kappa \mathrm{B}$ signaling in resident macrophages," Blood, vol. 118, no. 2, pp. 330-338, 2011.

[79] E. Sala, M. Genua, L. Petti et al., "Mesenchymal stem cells reduce colitis in mice via release of TSG6, independently of their localization to the intestine," Gastroenterology, vol. 149, no. 1, pp. 163-176.e20, 2015.

[80] J. Xie, H. E. Broxmeyer, D. Feng et al., "Human adiposederived stem cells ameliorate cigarette smoke-induced 
murine myelosuppression via secretion of TSG-6," Stem Cells, vol. 33, no. 2, pp. 468-478, 2015.

[81] G. J. Block, S. Ohkouchi, F. Fung et al., "Multipotent stromal cells are activated to reduce apoptosis in part by upregulation and secretion of stanniocalcin-1," Stem Cells, vol. 27, no. 3, pp. 670-681, 2009.

[82] C. M. Milner and A. J. Day, "TSG-6: a multifunctional protein associated with inflammation," Journal of Cell Science, vol. 116, Part 10, pp. 1863-1873, 2003.

[83] Y. Liu, R. Zhang, K. Yan et al., "Mesenchymal stem cells inhibit lipopolysaccharide-induced inflammatory responses of BV2 microglial cells through TSG-6," Journal of Neuroinflammation, vol. 11, no. 1, p. 135, 2014.

[84] R. Zhang, Y. Liu, K. Yan et al., "Anti-inflammatory and immunomodulatory mechanisms of mesenchymal stem cell transplantation in experimental traumatic brain injury," Journal of Neuroinflammation, vol. 10, no. 1, 2013.

[85] M. J. Lee, J. Kim, M. Y. Kim et al., "Proteomic analysis of tumor necrosis factor-alpha-induced secretome of human adipose tissue-derived mesenchymal stem cells," Journal of Proteome Research, vol. 9, no. 4, pp. 1754-1762, 2010.

[86] E. R. Andreeva, M. V. Lobanova, O. O. Udartseva, and L. B. Buravkova, "Response of adipose tissue-derived stromal cells in tissue-related $\mathrm{O} 2$ microenvironment to short-term hypoxic stress," Cells, Tissues, Organs, vol. 200, no. 5, pp.307-315, 2015.

[87] T. M. Rodríguez, A. Saldías, M. Irigo, J. V. Zamora, M. J. Perone, and R. A. Dewey, "Effect of TGF- $\beta 1$ stimulation on the secretome of human adipose-derived mesenchymal stromal cells," Stem Cells Translational Medicine, vol. 4, no. 8, pp. 894-898, 2015.

[88] A. A. Ostanin, Y. L. Petrovskii, E. Y. Shevela, and E. R. Chernykh, "Multiplex analysis of cytokines, chemokines, growth factors, MMP-9 and TIMP-1 produced by human bone marrow, adipose tissue, and placental mesenchymal stromal cells," Bulletin of Experimental Biology and Medicine, vol. 151, no. 1, pp. 133-141, 2011.

[89] S. Jessberger, R. E. Clark, N. J. Broadbent et al., "Dentate gyrus-specific knockdown of adult neurogenesis impairs spatial and object recognition memory in adult rats," Learning \& Memory, vol. 16, no. 2, pp. 147-154, 2009.

[90] N. Toni, D. A. Laplagne, C. Zhao et al., "Neurons born in the adult dentate gyrus form functional synapses with target cells," Nature Neuroscience, vol. 11, no. 8, pp. 901-907, 2008 .

[91] A. Shruster, H. Eldar-Finkelman, E. Melamed, and D. Offen, "Wnt signaling pathway overcomes the disruption of neuronal differentiation of neural progenitor cells induced by oligomeric amyloid $\beta$-peptide," Journal of Neurochemistry, vol. 116, no. 4, pp. 522-529, 2011.

[92] S. Jang, J. S. Park, and H. S. Jeong, "Neural differentiation of human adipose tissue-derived stem cells involves activation of the Wnt5a/JNK signalling," Stem Cells International, vol. 2015, 7 pages, 2015.

[93] H. Y. Ren, H. Xu, W. Y. Yu et al., "Potentiation of neuroal-like differentiation from rat adipose mesenchymal stem cells by Rho-associated coiled kinase inhibitor Y-27632," Chinese Journal of Anatomy, vol. 36, no. 4, pp. 772-809, 2013.

[94] R. A. Sabol, A. C. Bowles, A. Côté, R. Wise, N. Pashos, and B. A. Bunnell, "Therapeutic potential of adipose stem cells," in Advances in Experimental Medicine and Biology, Springer, New York, NY, 2018.
[95] B. F. Darst, R. L. Koscik, B. P. Hermann et al., "Heritability of cognitive traits among siblings with a parental history of Alzheimer's disease," Journal of Alzheimer's Disease, vol. 45, no. 4, pp. 1149-1155, 2015.

[96] R. E. Tanzi, "A brief history of Alzheimer's disease gene discovery," Journal of Alzheimer's Disease, vol. 33, Suppl 1, pp. S5-13, 2013.

[97] S. Kim, K. A. Chang, J. . Kim et al., "The preventive and therapeutic effects of intravenous human adipose-derived stem cells in Alzheimer's disease mice," Plos One, vol. 7, no. 9, p. e45757, 2012.

[98] X. Hu, R. K. Leak, Y. Shi et al., "Microglial and macrophage polarization-new prospects for brain repair," Nature Reviews Neurology, vol. 11, no. 1, pp. 56-64, 2015.

[99] R. Pérez-González, D. Antequera, T. Vargas, C. Spuch, M. Bolós, and E. Carro, "Leptin induces proliferation of neuronal progenitors and neuroprotection in a mouse model of Alzheimer's disease," Journal of Alzheimer's Disease, vol. 24, no. s2, pp. 17-25, 2011.

[100] W. Zhang, L. Zhang, N. Zhou et al., "Dysregulation of respiratory center drive (P0.1) and muscle strength in patients with early stage idiopathic Parkinson's disease," Frontiers in Neurology, vol. 10, p. 724, 2019.

[101] M. K. McCoy, T. N. Martinez, K. A. Ruhn et al., “Autologous transplants of Adipose-Derived Adult Stromal (ADAS) cells afford dopaminergic neuroprotection in a model of Parkinson's disease," Experimental Neurology, vol. 210, no. 1, pp. 14-29, 2008.

[102] A. Schwerk, J. Altschüler, M. Roch et al., "Human adiposederived mesenchymal stromal cells increase endogenous neurogenesis in the rat subventricular zone acutely after 6hydroxydopamine lesioning," Cytotherapy, vol. 17, no. 2, pp. 199-214, 2015.

[103] H. S. Choi, H. J. Kim, J. H. Oh et al., "Therapeutic potentials of human adipose-derived stem cells on the mouse model of Parkinson's disease," Neurobiology of Aging, vol. 36, no. 10, pp. 2885-2892, 2015.

[104] S. K. Kang, D. H. Lee, Y. C. Bae, H. K. Kim, S. Y. Baik, and J. S. Jung, "Improvement of neurological deficits by intracerebral transplantation of human adipose tissue-derived stromal cells after cerebral ischemia in rats," Experimental Neurology, vol. 183, no. 2, pp. 355-366, 2003.

[105] L. R. Zhao, W. M. Duan, M. Reyes, C. D. Keene, C. M. Verfaillie, and W. C. Low, "Human bone marrow stem cells exhibit neural phenotypes and ameliorate neurological deficits after grafting into the ischemic brain of rats," Experimental Neurology, vol. 174, no. 1, pp. 11-20, 2002.

[106] B. S. Bregman, E. Kunkel-Bagden, P. J. Reier, H. N. Dai, M. McAtee, and D. Gao, "Recovery of function after spinal cord injury: mechanisms underlying transplant-mediated recovery of function differ after spinal cord injury in newborn and adult rats," Experimental Neurology, vol. 123, no. 1, pp. 3-16, 1993.

[107] L. Cova, A. Ratti, M. Volta et al., "Stem cell therapy for neurodegenerative diseases: the issue of transdifferentiation," Stem Cells and Development, vol. 13, no. 1, pp. 121-131, 2004.

[108] A. Efimenko, E. Starostina, N. Kalinina, and A. Stolzing, "Angiogenic properties of aged adipose derived mesenchymal stem cells after hypoxic conditioning," Journal of Translational Medicine, vol. 9, no. 1, p. 10, 2011. 
[109] I. K. Moppett, “Traumatic brain injury: assessment, resuscitation and early management," British Journal of Anaesthesia, vol. 99, no. 1, pp. 18-31, 2007.

[110] B. E. Masel and D. S. DeWitt, "Traumatic brain injury: a disease process, not an event," Journal of Neurotrauma, vol. 27, no. 8, pp. 1529-1540, 2010.

[111] A. Dekmak, S. Mantash, A. Shaito et al., "Stem cells and combination therapy for the treatment of traumatic brain injury," Behavioural Brain Research, vol. 340, pp. 49-62, 2018.

[112] N. Tajiri, S. A. Acosta, M. Shahaduzzaman et al., "Intravenous transplants of human adipose-derived stem cell protect the brain from traumatic brain injury-induced neurodegeneration and motor and cognitive impairments: cell graft biodistribution and soluble factors in young and aged rats," Journal of Neuroscience, vol. 34, no. 1, pp. 313-326, 2014.

[113] T. Mert, A. H. Kurt, M. Arslan, A. Çelik, B. Tugtag, and A. Akkurt, "Anti-inflammatory and anti-nociceptive actions of systemically or locally treated adipose-derived mesenchymal stem cells in experimental inflammatory model," Inflammation, vol. 38, no. 3, pp. 1302-1310, 2015.

[114] J. M. Ziebell and M. C. Morganti-Kossmann, "Involvement of pro- and anti-inflammatory cytokines and chemokines in the pathophysiology of traumatic brain injury," Neurotherapeutics, vol. 7, no. 1, pp. 22-30, 2010.

[115] N. V. Selianina, I. V. Karakulova, and O. A. Eroshina, "The role of neuromediators and cytokines in the pathogenesis of acute traumatic brain injury," Zhurnal Voprosy Neirokhirurgii Imeni NN Burdenko, vol. 77, no. 6, pp. 22-26, 2013.

[116] S. M. Knoblach, L. Fan, and A. I. Faden, "Early neuronal expression of tumor necrosis factor- $\alpha$ after experimental brain injury contributes to neurological impairment," Journal of Neuroimmunology, vol. 95, no. 1-2, pp. 115-125, 1999.

[117] V. Trembovler, E. Beit-Yannai, F. Younis, R. Gallily, M. Horowitz, and E. Shohami, "Antioxidants attenuate acute toxicity of tumor necrosis factor-alpha induced by brain injury in rat," Journal of Interferon \& Cytokine Research, vol. 19, no. 7, pp. 791-795, 1999.

[118] N. S. Kappy, S. Chang, W. M. Harris et al., "Human adiposederived stem cell treatment modulates cellular protection in both in vitro and in vivo traumatic brain injury models," Journal of Trauma and Acute Care Surgery, vol. 84, no. 5, pp. 745-751, 2018.

[119] Y. Zhang, M. Chopp, Y. Meng et al., "Effect of exosomes derived from multipluripotent mesenchymal stromal cells on functional recovery and neurovascular plasticity in rats after traumatic brain injury," Journal of Neurosurgery, vol. 122, no. 4, pp. 856-867, 2015.

[120] S. K. Kapur and A. J. Katz, "Review of the adipose derived stem cell secretome," Biochimie, vol. 95, no. 12, pp. 22222228, 2013.

[121] S. M. Bird, H. R. Sohrabi, T. A. Sutton et al., "Cerebral amyloid- $\beta$ accumulation and deposition following traumatic brain injury-a narrative review and meta-analysis of animal studies," Neuroscience \& Biobehavioral Reviews, vol. 64, pp. 215-228, 2016.

[122] Y. Kishimoto, H. Shishido, M. Sawanishi et al., "Data on amyloid precursor protein accumulation, spontaneous physical activity, and motor learning after traumatic brain injury in the triple-transgenic mouse model of Alzheimer's disease," Data in Brief, vol. 9, no. C, pp. 62-67, 2016. 


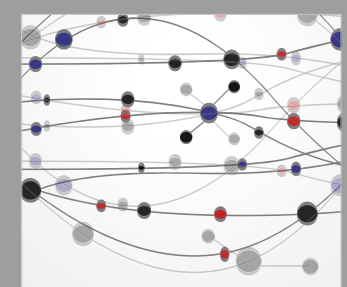

The Scientific World Journal
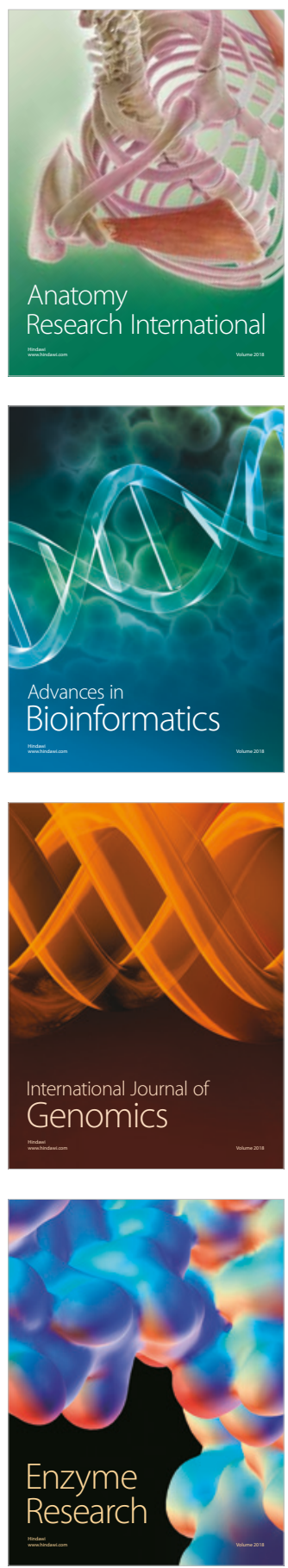
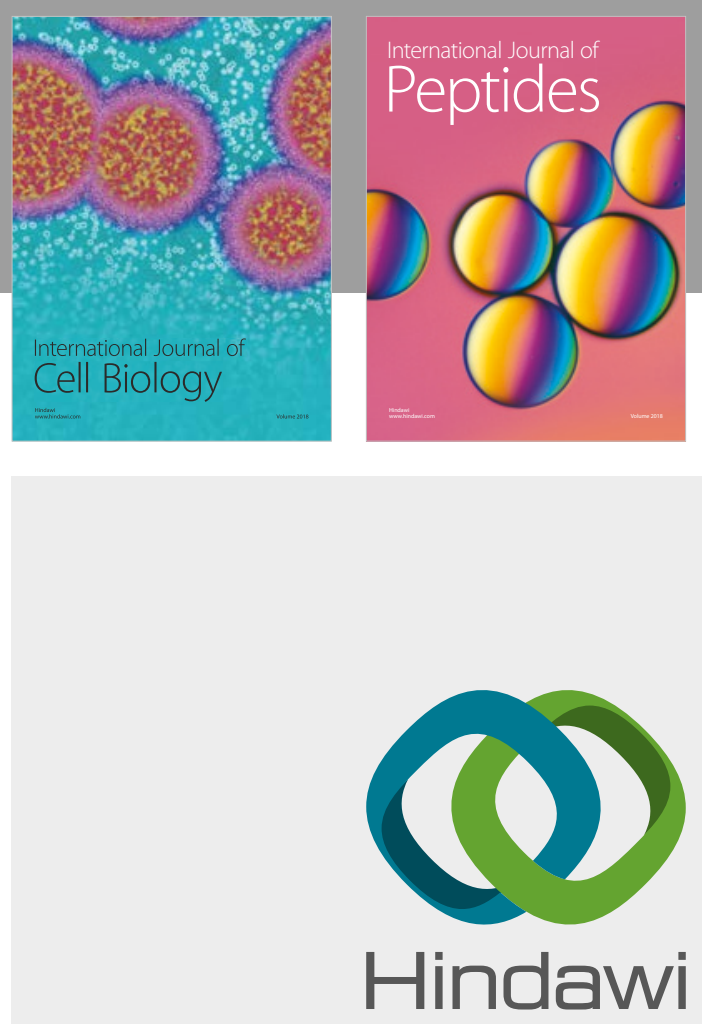

Submit your manuscripts at

www.hindawi.com
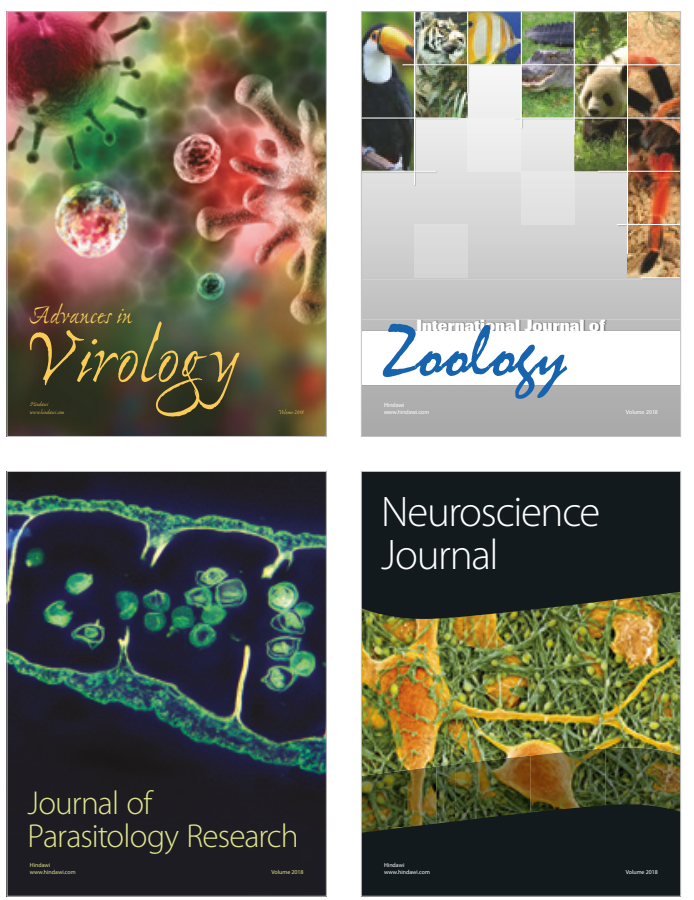
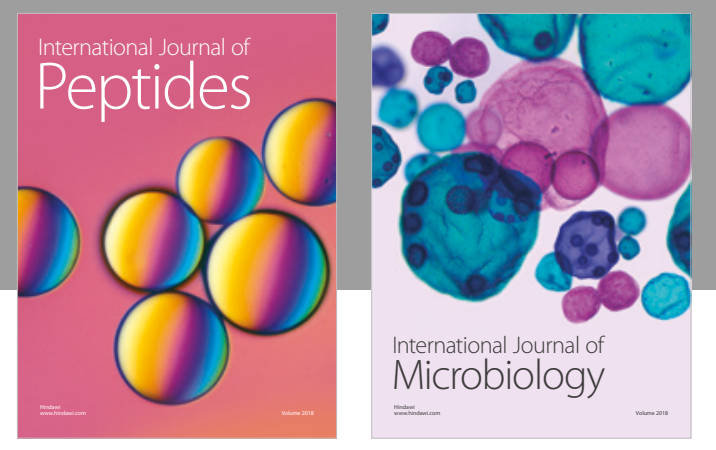

nternational Journal of Microbiology
Journal of
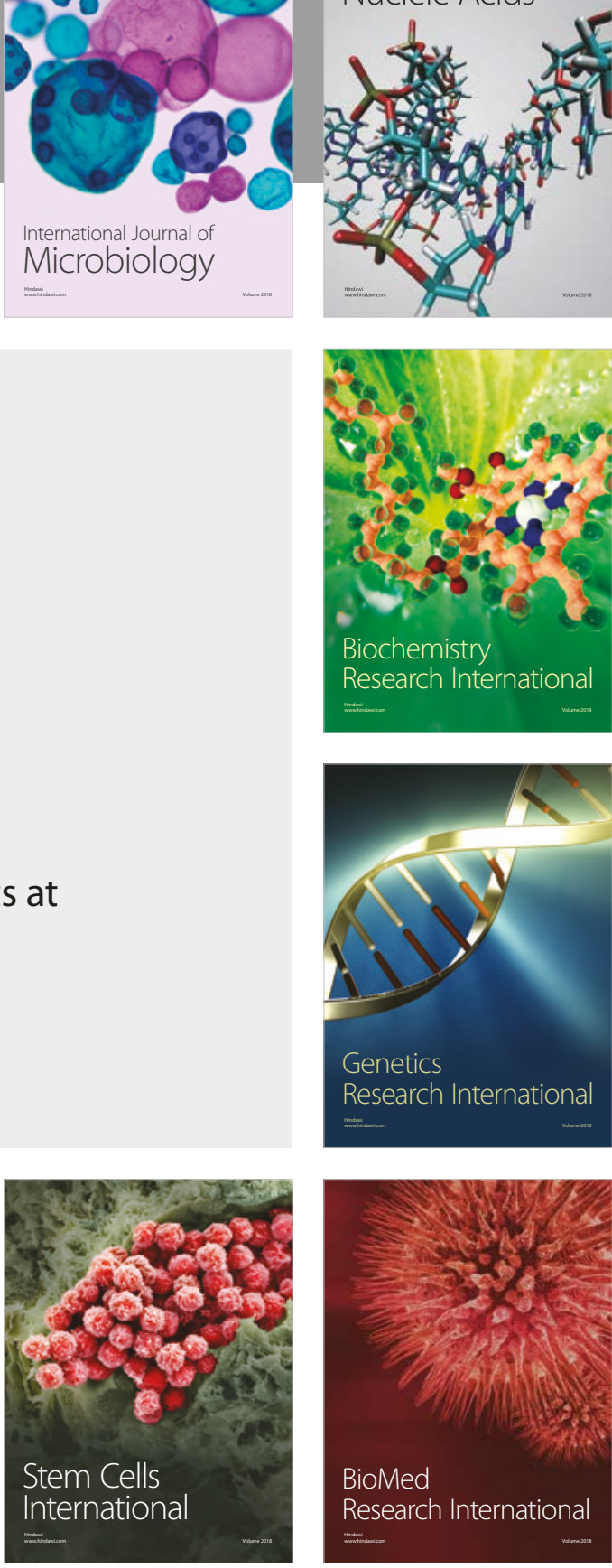
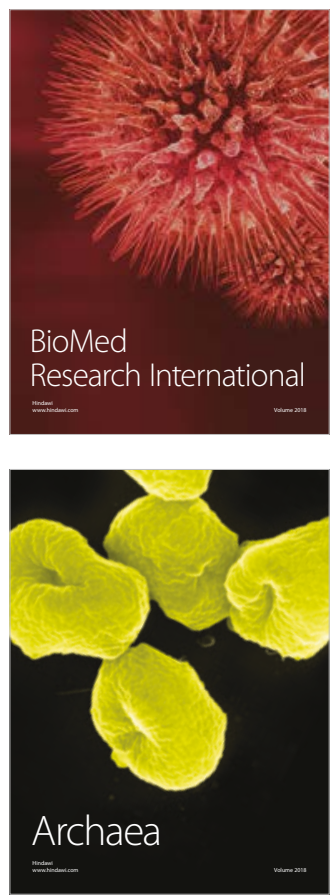